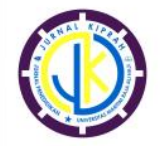

http://ojs.umrah.ac.id/index.php/kiprah

p-ISSN 2354-7278 | e-ISSN 2580-6947

\title{
Efektivitas Penggunaan Simulasi dengan Multisim Berbantuan Virtual Laboratory untuk Meningkatkan Kemampuan Berpikir Kritis Mahasiswa Jurusan Pendidikan Teknik Elektro
}

\author{
Ridwan*, Djubir Ruslan Edi Kembuan \\ Pendidikan Teknik Elektro, Universitas Negeri Manado, Minahasa, Indonesia \\ Pengiriman: 22/04/2021; Diterima: 08/06/2021; Publikasi: 29/06/2021 \\ DOI: 10.31629/kiprah.v9i1.3235
}

\begin{abstract}
Abstrak
Adanya anjuran pemerintah dalam mengalihkan sementara pembelajaran tatap muka ke pembelajaran jarak jauh dikarenakan pandemi covid 19 yang masih tinggi membuat para pendidik sulit mengutarakan maksud dan tujuan pembelajaran ke peserta didik. Apalagi dengan pembelajaran praktikum, hal ini akan menjadi sulit terealisasikan dengan baik. Sebenarnya pembelajaran praktikum dimasa pandemi covid 19 saat ini bisa dilakukan untuk peserta didik dalam meningkatkan kemampuan berpikir kritis asalkan didukung semacam peralatan lab yang memadai dalam sebuah aplikasi. Mengatasi hal itu, maka perlu semacam penggunaan multisim dengan bantuan virtual lab dalam praktikum. Penelitian ini bertujuan mengetahui efektivitas penggunaan multisim dengan bantuan virtual laboratory untuk meningkatkan kemampuan berpikir kritis peserta didik mata kuliah praktikum rangkaian listrik jurusan pendidikan teknik elektro. Metode penelitian yang dilakukan ialah eksperimen semu dengan rancangan penelitian pretest-posttest control group design. Pengumpulan data berupa tes dan dokumentasi selama penelitian berlangsung. Analisis data berupa yang digunakan adalah uji $t$-test. Hasil penelitian menunjukkan $t$ test $>t$ table $(3,82>1,99)$ maka Ho ditolak dan Ha diterima. Dengan demikian ditarik kesimpulan bahwa ternyata penggunaan simulasi multisim berbantuan virtual laboratory pada pembelajaran praktikum rangkaian listrik efektif secara signifikan dalam meningkatkan kemampuan berpikir kritis mahasiswa.
\end{abstract}

Kata kunci: kemampuan berpikir kritis; pembelajaran multisim; virtual laboratory

\begin{abstract}
The government recommends switching to distance learning due to the high Covid 19 pandemi making it difficult for educators to express the aims and objectives of learning to students. Moreover, practicum learning becomes difficult to implement properly. Actually practicum learning at this time can be done for students in improving critical thinking ability as long as it is supported by laboratory equipment application need some sort of use of multisim with the help of virtual lab in practicum. This study aims to determine effectiveness of using multisim with the help of a virtual laboratory to improve critical thinking ability of students in the electrical circuit practicum. The research method used was quasi-experimental research design with pretest-posttest control group design. Data collection in the form of tests and documentation during the study. The data analysis used was the ttest. The results showed that $\mathrm{t}$ test $>\mathrm{t}$ table $(3.82>1.99)$ then Ho was rejected and Ha was accepted. The conclusion is that it turns out that the use of virtual laboratory assisted multisimsimulations in practicum learning of electric circuits is significantly effective in improving students' critical thinking ability.
\end{abstract}

Keywords: critical thinking ability; multisim learning; virtual laboratory 


\section{PENDAHULUAN}

Indonesia merupakan salah satu negara yang berdampak sekali kondisi yang cukup memperihatinkan akibat covid 19 ini. Banyak anjuran pemerintah yang mengupayakan masyarakat lebih fokus mematuhi protokol kesehatan dan lebih memprioritaskan masyarakat lebih baik di rumah saja. Salah satu kondisi inilah yang memungkinkan penyelengaraan pendidikan di sekolah-sekolah baik tingkat anak usia dini hingga perguruan tinggi ikut berkontribusi mematuhi anjuran pemerintah di masa pandemik covid 19 ini dengan meliburkan sementara dan beralih status untuk belajar di rumah dengan upaya pembelajaran daring.

Hakekatnya pembelajaran daring ini mengharuskan para guru ataupun dosen terutama di perguruan tinggi harus terampil menciptakan suasana pembelajaran secara virtual tanpa tatap muka yang tidak mengenal jarak ataupun batasan waktu agar kemampuan pembelajaran di masing-masing peserta didik mampu terserap penyampaian belajar secara daring. Disamping itu pula, para peserta didik walaupun keterbatasan kondisi mengingat masih ada wabah virus covid 19, perlu mematuhi dan melaksanakan kegiatan pembelajaran secara daring serta melek terhadap teknologi ketika menggunakannya.

Lebih sulitnya lagi, apalagi dikarenakan semua mata kuliah baik secara terori maupun praktikum di alihkan ke semua pembelajaran daring jelas mengurangi kreativitas kemampuan siswa terutama di mata kuliah praktikum (Argaheni, 2020). Oleh sebab itu perlu upaya pemahaman baru yang efektif dari para pendidik khususnya mata kuliah praktikum di cari solusi agar kegiatan belajar mengajar dapat terjalin lebih maksimal baik secara secara formal maupun nonformal seperti daring saat ini untuk memperoleh hasil pembelajaran yang efektif dan berkualitas. Kemudian mereka mampu aktif dan berpikir setidaknya sama dengan pembelajaran luring atau tatap muka langsung di laboratorium.
Pembelajaran yang efektif dan berkualitas haruslah ada dukungan beberapa unsur salah satunya yaitu perangkat pembelajaran yang memadai yang bisa membantu para peserta didik mengetahui, memahami, dan mengimplementasikan pengetahuan serta keterampilan di saat pembelajaran saat ini (Ayuningtyas dkk, 2017). Upaya agar meningkatkan nilai peserta didik maka perlu adanya dorongan kuat dari aspek kegiatan-kegiatan maupun program belajar yang mengarah pada kualitas kompetensi serta nilai bersaing dalam belajar (Sastroprawiro, 2011). Oleh karena itu, perlunya kegiatan pembelajaran yang menghasilkan mahasiswa mampu menggunakan teknologi. Salah satunya dengan pembelajaran yang mengarah pada kontekstual (Royani et al., 2018).

Namun kenyataanyan, berdasarkan observasi awal yang peneliti lakukan pada saat pembelajaran daring terutama mata pelajaran praktikum seperti rangkaian listrik, pendidik merasa kebingungan dalam melaksanakan praktikum berdasarkan pembelajaran daring apalagi hal ini tidak terjadi secara tatap muka antara pendidik dengan peserta didik. Kesulitan pendidik memberikan tugas kerja praktikum kepada peserta didik di saat daring ini membuat kualitas cara pembelajaran pendidik sedikit menurun. Maka perlu semacam inovasi baru dalam menemukan solusi pasti pada pembelajaran

Lebih lanjut, selama masa pandemi covid 19, pembelajaran yang dilakukan secara daring dalam hal penyampaikan pembelajaran praktikum menimbulkan kendala seperti mahasiswa yang tidak bisa menggunakan alat ukur dan arus tegangan secara fisik melainkan hanya berupa gambar-gambar yang ditampilkan melalui pembelajaran online. Selain itu, dikarenakan mahasiswa tidak melihat objek pembelajaran yang dijelaskan melalui offline sehingga kurang mendalami materi. Untuk itu, perlu adanya solusi dalam mengatasi keterbatasan dalam penjelasan pembelajaran pratikum khususnya mata kuliah praktikum rangkaian listrik. Oleh sebab itu, 
perlu cara efektif dalam pembelajaran yang mengarahkan pada penerapan aplikasi dan dukungan virtual lab yang memungkinkan dapat meminimalisir ketidaktahuan peserta didik dalam belajar serta membuktikan sendiri secara personal melalui keterampilan dalam menggunakan aplikasi multisim dan virtual lab tersebut.

Multisim adalah sebuah aplikasi yang diproduksi oleh National Instruments Inc yang mampu menjalankan program spesifik untuk rangkaian listrik maupun elektronika yang dapat dengan mudah mengamati gejala rangkaian listrik yang di simulasikan dan melakukan uji pengukuran yang spesifik data yang lebih akurat serta didukung beberapa komponen rangkaian yang sangat kompleks (Báez-López \& Guerrero-Castro, 2011). Sedangkan virtual lab dari phet adalah software online yang dibuat oleh kampus ternama yaitu University of Colorado yang mengembangkan dari teknologi pembelajaran fisika yang mampu mendemonstrasikan bentuk flowchart rangkaian agar peserta didik mengenal secara utuh rangkaian tersebut (Tüysüz, 2010).

Menurut Putra (2009) mengemukakan bahwa laboratorium merupakan sebuah perangkat aplikasi secara online dimana diperuntukan bagi para pendidik, instruktur, maupun masyarakat umum dijadikan tempat untuk melakukan percobaan dari teori yang didapat dengan membuktikan melalui aplikasi tersebut. Laboratorium virtual adalah ruang kerja elektronik untuk kolaborasi yang membuktikan eksperimen antara teori dengan implementasi praktikum melalui simulasi tanpa mengenal jarak ataupun waktu dalam kreativitas pembuktian dalam praktikum serta menghasilkan dan memberikan dampak pengetahuan yang nyata dalam pemberian informasi pembelajaran (Simbolon, 2015). Di samping itu adanya virtual laboratorium memungkinkan dapat mensimulasikan eksperimen dari laboratorium secara fisik, dibuat untuk tujuan memberikan instruksi kepada peserta didik dalam menggunakan fasilitas laboratorium yang secara pengoperasiannya menghasilkan hasil yang mirip dengan nyata menduplikasi pengalaman seseorang terutama pelajaran rangkaian listrik.

Materi rangkaian listrik pada intinya merupakan pembelajaran dasar kelistrikan yang harus diketahui peserta didik yang mengambil jurusan elektro. Ilmu elektro tidak terlepas dari rangkaian listrik yang perlu dipahami oleh peserta didik. Walaupun secara teori rangkaian listrik hanya bisa dijabarkan secara teori maupun analisis perhitungan, setidaknya ketika praktikum perlu adanya pembuktian yang nyata dengan dilakukan eksperimen melalui aplikasi multisim maupun bantuan virtual lab. Itulah kesempatan bagi peserta didik untuk melakukan percobaan dan menentukan jenis percobaan yang akan dibuat serta akan diselesaikan menggunakan VLab yang memungkinkan siswa untuk memahami konsep kimia dan untuk meningkatkan kesempatan bereksperimen bagi siswa untuk menentukan jenis percobaan mereka ingin melakukan (Herga et al., 2016)

Pembelajaran praktikum rangkaian listrik bisa diterapkan dengan aplikasi multisim maupun virtual lab, seperti pembuktian konsep hukum kirchoff, ohm, teorema thevenin, northon, superposisi, dan pengukuran berbagai macam kelistrikan.

Menurut Dalgarno et al., (2009) mengemukakan bahwa keefektifan lingkungan virtual berdasarkan laboratorium sebagai alat untuk mempersiapkan peserta didik yang belajar dari jarak jauh. Begitupula (Maksum dan Saragih (2020) mengemukakan bahwa ketika dilakukan penerapan virtual lab, ternyata dapat mengatasi akan kekurangan dalam kesalahan dalam berkerja serta mengurangi pula kecelakaan pada saat melaksanakan praktikum di era pandemi covid 19 saat ini. Selain itu virtual lab juga dijadikan prioritas yang efektif saat ini dapat menjadi solusi bagi perguruan tinggi terutama pada keterbatasan saran prasarana serta kodisi lingkungan yang saat ini tidak memungkinkan untuk sepenuhnya dilakukan secara luring. Dengan demikian dari 
beberapa dukungan para peneliti perlu adanya gagasan dalam pembelajaran akan multisim yang dikolaborasikan dengan virtual lab. Dengan adanya multisim, seseorang akan lebih mudah melakukan rekayasa dalam bentuk permodelan dari karakteristik sebuah rangkaian listrik dengan mengetahui berapa besaran arus, tegangan maupun bentuk gelombang yang dihasilkan dalam rangkaian tersebut. Kemudian dengan dukungan kuat bantuan dari virtual lab membuat rangkaian yang telah jadi tersebut dapat mengetahui arah arus yang mengalir pada rangkaian. Hal ini dijadikan sebagai tindak lanjut penyampaian informasi dalam mata kuliah praktikum khususnya rangkaian listrik agar lebih terampil dalam menganalisi permasalahan yang dituntut berpikir kritis saat pembelajaran.

Kemampuan berpikir kritis (critical thinking ability) sebagai tolak ukur kemampuan yang ada pada diri manusia secara kualitas mampu untuk mengetahui dan bernalar akan kekritisan di lingkungan sekitar yang terlibat aktif berdasarkan pengetahuan serta cepat tanggap (Williams \& Williams, 2011). Ennis dan Lau (2011) berpendapat bahwa seseorang yang dikatakan berpikir kritis akan mampu beradaptasi dengan memahami karakteristik dirinya melalui beberapa tahapan mulai dari mengidentifikasi permasalahan yang ada disekitarnya, memahami permasalahan, menganalisis permasalahan menjadi lebih sederhana, mengevaluasi, dan merumuskan pemecahan masalah untuk bisa dicarikan solusi yang terukur dan efektif. Dengan demikian sangat perlu adanya gambaran seorang pendidik terutama dalam mengelola kegiatan pembelajaran praktikum untuk berpikir kritis terutama pada praktikum yang dijalankan pada masa pandemi covid 19 saat ini.

\section{METODE PENELITIAN}

Pada penelitian ini dilakukan untuk memperoleh capaian hasil data dan tujuan yang ingin di capai oleh peneliti pada saat melakukan pengamatan. Metode penelitian yang peneliti lakukan dalam bentuk eksperimen semu atau dikenal dengan istilah quasy eksperimental design. Selanjtunya rancangan penelitian yang dilakukan menggunakan cara pretest- posttest kontrol group design yang dilihat pada Tabel 1 dibawah ini.

Tabel 1. Rancangan Penelitian

\begin{tabular}{lrcc}
\hline Kelompok & Pretest & Perlakuan & Posttest \\
\hline Eksperimen & $\mathrm{O} 1$ & $\mathrm{X} 1$ & $\mathrm{O} 1$ \\
Kontrol & $\mathrm{O} 2$ & $\mathrm{X} 2$ & $\mathrm{O} 2$ \\
\hline
\end{tabular}

Keterangan:

O1 dan O2: hasil yang diperoleh

$\mathrm{X} 1$ dan X2: sebagai perlakuan saat penelitian

Pada kesempatan kali ini, penelitian hanya menggunakan subjek penelitian mahasiswa semester 4 jurusan pendidikan teknik elektro berjumlah 43 peseta didik yang mengambil mata kuliah praktek rangkaian listrik. Kelompok eksperimen terdiri dari 21 peserta didik sedangkan kelompok kontrol terdiri dari 22 peserta didik. Kelompok eksperimen diberikan perlakuan dengan penjelasan daring menggunakan multisim dengan virtual lab berupa Lab Virtual Phet dan kelompok kontrol dengan penjelasan secara daring dengan virtual lab berupa Lab Virtual Phet. sebagaimana dapat dilihat pada gambar dibawah ini.

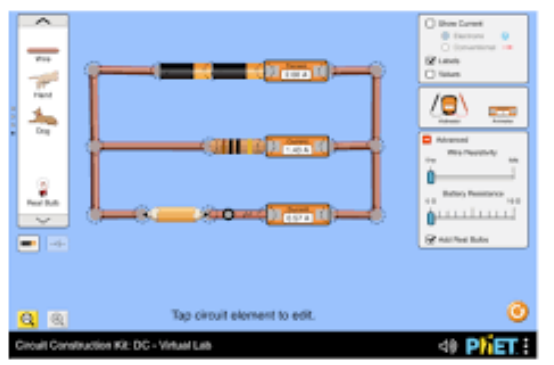

Gambar 1. Lab Virtual Phet

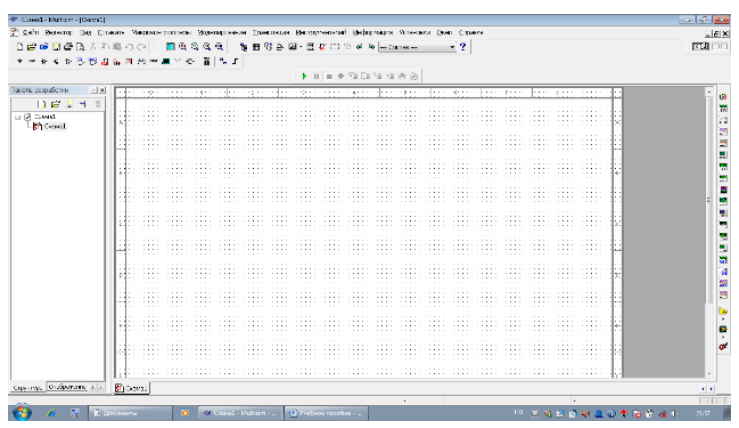

Gambar 2. Multisim

Selanjutnya, teknik pengumpulan data berua tes dan dokumentasi selama mengikuti 
proses pembelajaran penelitian. Tes yang lakukan yaitu indikator kemampuan berpikir kritis yang mana aspek tes dilakukan berdasarkan 5 indikator kemampuan berpikir kritis yaitu mengidentifikasi, memahami, menganalisis, mengevaluasi, dan menyimpulkan. Kemudian teknik analisis data berupa uji normalitas menggunakan komogorov smirnov, uji homogenitas menggunakan homogeneity test dan uji hipotesis dilakukan dengan uji T pada program SPSS 18. Hasil tes kemampuan berpikir kritis setelah diuji kepada peserta didik, nantinya dikumpulkan hasil pretest dan posttest lalu dimasukan pada program spss untuk dilakukan pengolahan data dievaluasi serta dibuat kesimpulan.

\section{HASIL DAN PEMBAHASAN}

Penelitian dilaksanakan pada pembelajaran daring berupa zoom ataupun google classroom yang mengharuskan pendidik untuk memberi penyampaian informasi disana. Terkait mata kuliah praktikum pun dilaksanakan pada pembelajaran daring untuk peserta didik semester 5 tahun ajaran 2020/2021. Selanjutnya objek penelitian meliputi kelas elektro A dan elektro B yang berjumlah 43orang. Mahasiswa tersebut sudah terbagi kedalam system pembelajaran dijurusan yang terbagi atas kelas elektro A berjumlah 21 orang dan kelas elektro B berjumlah 22 orang.

Penelitian dilakukan selama 6 minggu pertemuan, yang mana 3 minggu untuk kelas eksperimen dan 3 minggu untuk kelas kontrol masing-maisng durasi waktu yaitu $3 \times 45$ menit. Selama proses kegiatan penelitian dilaksanakan, peneliti akan memberikan semacam tes awal dan tes akhir untuk mengetahui sejauh mana mereka dapat memahami dan mendalami materi yang telah terserap. Berikut ini hasil perolehan data untuk mengetahui seberapa besar rerata peserta didik untuk kekampuan berpikir kritis pada saat diberikan tes awal (pretest) pada Tabel 2 berikut ini.
Tabel 2. Hasil Perolehan Data Pretest untuk Eksperimen dan Kontrol

\begin{tabular}{lccccc}
\hline Kelas & $\mathrm{N}$ & Min & Max & Mean & $\begin{array}{c}\text { Std. } \\
\text { Deviation }\end{array}$ \\
\hline Eksperimen & 21 & 5.00 & 25.00 & 11.19 & 5.89 \\
Kontrol & 22 & 5.00 & 20.00 & 9.318 & 4.16 \\
Valid N & & & & & \\
\hline
\end{tabular}

Berdasarkan perolehan yang didapat di Tabel 2 diatas, maka dapat dijelaskan bahwa ternyata untuk nilai rerata sementara pada kedua kelas sebelum dilakukan perlakuan mengalami hasil yang tidak jauh berbeda dikedua hasilnya. Hal ini dapat dijelaskan bahwa nilai rerata prolehan hasil peserta didik untuk kelas eksperimen sebesar 11,19 yang mana untuk minimum diperoleh terkecil 5 dan untuk nilai maksimum diperoleh 25 serta standar deviasi 5,89. Begitupula untuk nilai rerata kelas kontrol sebesar 9,318 yang mana untuk nilai minimum peserta didik 5 dan untuk nilai maksimum 20 serta standar deviasi 4,16. Selanjutnya berikut perolehan data untuk mengetahui seberapa besar rerata peserta didik untuk kekampuan berpikir kritis pada saat diberikan tes akhir (posttest) pada Tabel 3 berikut ini

Tabel 3. Hasil Perolehan Data Posttest untuk Eksperimen dan Kontrol

\begin{tabular}{lccccc}
\hline Kelas & N & Min & Max & Mean & $\begin{array}{c}\text { Std. } \\
\text { Deviation }\end{array}$ \\
\hline $\begin{array}{l}\text { Eksperim } \\
\text { en }\end{array}$ & 21 & 75 & 100 & 88.09 & 8.288 \\
$\begin{array}{l}\text { Kontrol } \\
\text { Valid N }\end{array}$ & 22 & 75 & 95 & 80.00 & 5.345 \\
\hline
\end{tabular}

Berdasarkan perolehan yang didapat di Tabel 3 diatas, maka dapat dijelaskan bahwa ternyata setelah diberikan tes akhir, diperoleh nilai rerata peserta didik mengalami perbedaan diantara keduanya. Hal ini dapat dijelaskan bahwa nilai rerata prolehan hasil peserta didik untuk kelas eksperimen sebesar 88,09 yang mana untuk minimum diperoleh terkecil 75 dan untuk nilai maksimum diperoleh 100 serta standar deviasi 8,288. Begitupula untuk nilai rerata kelas kontrol sebesar 80,00 yang mana untuk nilai minimum peserta didik 75 dan untuk nilai maksimum 95 serta standar deviasi 5,345. 
Jadi dengan demikian secara analisis, peroleh hasil data di kedua kelas menunjukkan bahwa pembelajaran diantara kedua kelas mengalami perbedaan yang cukup signifikan. Artinya disini, peserta didik ketika diberi perlakuan selama pembelajaran praktikum diera pandemi covid 19 dengan memakai simulasi software multisim dengan virtual lab dapat lebih leluasa memudahkan peserta didik bereksperimen sehingga inovatif terserap pengetahuan yang diperolehnya dibanding hanya pembelajaran daring pada penjelasan di virtual lab.

Sejalan dengan Maksum dan Saragih (2020) menyatakan bahwa pembelajaran praktikum dengan virtual lab yang didukung aplikasi lebih efektif diterapkan kepada mahasiswa untuk menunjang pemahaman praktik dibandingkan reality lab yang keterbatasan alat dan kebutuhan praktikum.

Selanjutnya untuk mengetahui perolehan data kedua kelas tersebut berdistribusi normal, maka perlu semacam perhitungan dengan menggunakan SPSS versi 18 dengan Kolmogrov Smirnov. Distribusi kedua kelas dikatakan normal setelah dilakukan uji coba untuk mengetahui berapa besar kenormalannya dengan menggunakan uji Normalitas. Berikut ini perolehan data uji normalitas kelas eksperimen dan kelas kontrol pada Tabel 4 berikut ini

Tabel 4. Perolehan Data Uji Normalitas dengan One-Sample Kolmogorov-Smirnov

\begin{tabular}{|c|c|c|c|}
\hline & & Eksperimen & Kontrol \\
\hline $\mathrm{N}$ & & 21 & 22 \\
\hline \multirow{2}{*}{$\begin{array}{l}\text { Normal } \\
\text { Parameters }\end{array}$} & Mean & $88.09 \mathrm{j}$ & 80.00 \\
\hline & $\begin{array}{l}\text { Std. } \\
\text { Deviation }\end{array}$ & 8.28797 & 5.34522 \\
\hline \multirow{2}{*}{$\begin{array}{l}\text { Most Extreme } \\
\text { Differences }\end{array}$} & Absolute & .217 & .273 \\
\hline & $\begin{array}{l}\text { Positive } \\
\text { Negative }\end{array}$ & $\begin{array}{l}.217 \\
.131\end{array}$ & $\begin{array}{l}.273 \\
.175\end{array}$ \\
\hline $\begin{array}{l}\text { Kolmogorov- } \\
\text { Smirnov Z }\end{array}$ & & .993 & 1.279 \\
\hline $\begin{array}{l}\text { Asymp. Sig. (2- } \\
\text { tailed) }\end{array}$ & & .278 & .076 \\
\hline
\end{tabular}

Berdasarkan perolehan yang didapat di Tabel 4 diatas, menunjukan bahwa hasil data untuk uji normalitas di kedua kelas yaitu eksperimen sebesar 0,278 dan kontrol sebesar 0,076. Jika ketentuan bagi seseorang dalam melakukan uji normalitas ternyata $\mathrm{P}$ value > 0,05, maka Ho diterima. Dengan demikian menunjukkan perolehan hasil data di kedua kelas seperti eksperimen dan kontrol berdisitribusi normal. Selanjutnya Berikut ini perolehan data uji homogenitas untuk mengetahui varian data kemampuan berpikir kritis pada kelas eskperimen dan kontrol pada Tabel 5 berikut ini

Tabel 5. Perolehan Data Uji Homogenitas pada Eksperimen dan Kontrol

Kemampuan

Berpikir Kritis

Levene Statistic df1 df2 Sig.

$\begin{array}{llll}9.759 & 1 & 41 & .803\end{array}$

Berdasarkan perolehan yang didapat di Tabel 5 diatas, menunjukan bahwa hasil data untuk uji homogenitas di kedua kelas yaitu eksperimen dan kontrol mengalami signifikansi sebesar 0,803 yang artinya $>0,05$. Sebagaimana dasar dalam mengambil keputusan pada pengujian kali ini bahwa memiliki varian yang sama. Dengan demikan, varian data dari kemampuan berpikir kritis peserta didik didalam proses pembelajaran praktikum rangkaian listrik elektro A dan Elektro B adalah sama atau homogen.

Setelah dilakukan perhitungan hasil data analisis pada kedua kelas baik normalitas, dan homogenitas, maka langkah berikutnya adalah melakukan pembuktian hipotesis hasil akhir uji t- test dengan program SPSS versi 28. Berikut ini perolehan data uji t- test pada Tabel 6 berikut ini

Tabel 6. Hipotesis Uji Test (t-test)

\begin{tabular}{ccccccc}
\hline \multicolumn{5}{c}{$\begin{array}{c}\text { Levene's Test } \\
\text { for Equality of } \\
\text { Variances }\end{array}$} & & t-test for Equality \\
\cline { 2 - 7 } & $\mathrm{F}$ & Sig. & $\mathrm{t}$ & $\mathrm{df}$ & $\begin{array}{c}\text { Sig. (2- } \\
\text { tailed) }\end{array}$ \\
\hline $\begin{array}{c}\text { Post } \\
\text { test }\end{array}$ & $\begin{array}{c}\text { Equal } \\
\text { variances } \\
\text { assumed } \\
\text { Equal } \\
\text { Eariances } \\
\text { not } \\
\text { assumed }\end{array}$ & 9.76 & .803 & 3.82 & 41 & .001 \\
\hline
\end{tabular}




\section{Berdasarkan perolehan yang} didapat di Tabel 6 diatas, dijelaskan bahwa perolehan hasil t hitung atau $t$ test sebesar 3,82. Jika dilakukan perhitungan dengan mengunakan acuan 0,05 maka terlebih dahulu hitung derajat kebebasan (df) $41-2=39$, yang mana di t table menjadi acuan diperoleh adalah 1,99. Dengan demikian jika di peroleh acuan data yang didapat $t$ test $>$ t table $(3,82>1,99)$ maka Ho ditolak dan Ha diterima. Asumsi yang diperoleh ditarik kesimpulan bahwa ternyata penggunaan simulasi multisim berbantuan virtual laboratory pada pembelajaran praktikum rangkaian listrik efektif meningkatkan kemampuan berpikir kritis mahasiswa dibandingkan dengan penggunaan virtual laboratory yang diperoleh saat pembelajaran daring.

Selanjutnya setelah selesai melakukan penelitian, maka peneliti memperoleh pengamatan yang baik merubah pola pembelajaran yang lebih terarah dan mampu peserta didik terlibat aktif dan kritis dalam melaksanakan pembelajaran praktikum seperti rangkaian listrik yang dilakukan selama daring.. Selama pengamatan peneliti lakukan untuk kelas eksperimen yang menggunakan simulasi multisim dengan bantuan virtual lab sebagai penguat penugasan praktikum ternyata efektif peserta didik dalam membuktikan data yang didapat serta lebih leluasa dalam bereksperimen dengan hal-hal baru baik berupa perubahan pola angka, maupun pola rangkaian listrik yang berbeda.

Pada sisi lainnya, penggunaan multisim yang menunjang kreativitas mahasiswa, dimana dilengkapi fitur-fitur berupa alat pengukuran, komponen-komponen bahan, hingga dapat menampilkan rangkaian dalam bentuk 3D. Dukungan ini juga diperkuat dengan adanya virtual lab sebagai pembanding ke dua simulasi. Jadi tidak menutup kemungkinan dengan adanya eksperimen dengan pola-pola yang baru di dapat oleh peserta didik dan didukung dengan pembuktian teori yang didapat, tidak heran jika percapaian kemampuan berpikir kritis akan berkembang selama kegiatan berlangsung.

Begitupula dengan pengamatan peneliti lakukan pada pembelajaran praktikum berupa pembelajaran daring dengan virtual lab yang terbatas dengan beberapa fitur didalamnya. Namun tidak menutup kemungkinan ada juga yang beberapa job praktikum bisa menyesuaikan keadaan dalam penggunaan simulasi yang ada di virtual lab. Terkadang pola simulasi di virtual lab masih butuh memperkuat kajian yang didapat oleh peserta didik untuk sebagai perbandingan dengan analisis perhitungan secara manual. Dengan demikian upaya kritis dan keaktifan peserta didik dalam pengerjaanya sudah cukup namun perlu mendorong untuk lebih berkreativitas. Hasil inilah yang dibuktikan dengan semacam tes berupa soal diperoleh untuk menjadikan perbandingan dengan yang kedua kelompok penelitian.

Adanya penggunaan multisim dengan bantuan virtual lab merupakan solusi yang cukup baik dalam mengatasi keterhambatan dalam menjalankan praktikum terutama pada praktek rangkaian listrik mengingat masa pandemi saat ini masih belum memungkinkan untuk melakukan tatap muka secara luring sesuai anjuran pemerintah. Selain itu efektif peserta didik menjadi lebih bersemangat mengkreasikan dan bereksperimen untuk menstimulasikan pengalaman belajar melalui pembelajaran praktikum sebagai motivasi, minat dan meningkatkan kemampuan berpikir kritis peserta didik (Nurhayati, 2017).

Pada sisi lainnya, adanya dukungan virtual lab dengan aplikasi berguna untuk mempengaruhi cara pembelajaran yang lebih mengindikasikan perilaku disiplin, teliti, jujur dan mampu berkerjasama satu sama lain dalam memecahkan persoalan yang perlu dikaji secara eksperimen saat mengukur dan dibuktikan dengan teori perhitungan analisis dalam praktikum (Dewi \& Prasetiyo, 2015). Hal inilah yang membuat peran pendidik dapat mempermudah dalam membimbing dan mengarahkan objek permasalahan dalam mengembangkan potensi belajar saat praktikum lebih mandiri serta meningkat cara belajar 
peserta didik (Wijaya, 2017). Mengingat pandemi saat ini upaya pendidik perlu mendemonstrasikan penyampaian informasi pembelajaran mata kuliah praktikum yang justru tidak bisa dilakukan secara tatap muka di tempat laboratorium. Adanya cara ini memberikan keleluasaan kepada peserta didik untuk melaksanakan dan tetap praktik secara maksimal dimana saja tanpa mengenal jarak dan waktu (Sutrisno, 2012). Dengan demikian sudah jelas di masa saat ini dapat menjadikan solusi yang sangat baik dalam melaksanakan praktikum.

\section{KESIMPULAN}

Hasil penelitian ini menunjukkan bahwa penggunaan simulasi multisim berbantuan virtual laboratory pada pembelajaran praktikum rangkaian listrik efektif meningkatkan kemampuan berpikir kritis mahasiswa dibandingkan dengan penggunaan virtual laboratory yang diperoleh saat pembelajaran daring. Selama pembelajaran praktikum rangkaian listrik, pembelajaran yang menggunakan multisim dengan virtual laboratory lebih baik serta leluasa memudahkan peserta didik bereksperimen sehingga inovatif terserap pengetahuan yang diperolehnya dibanding hanya pembelajaran daring pada penjelasan di virtual lab. Peserta didik lebih senang penggunaan simulasi multisim berbantuan virtual laboratory pada pembelajaran praktikum rangkaian listrik efektif meningkatkan kemampuan berpikir kritis mahasiswa dibandingkan dengan penggunaan virtual laboratory yang diperoleh saat pembelajaran daring.

Hasil yang diperoleh pada saat sebelum (pretest) dan sesudah (posttest) perlakuan menunjukkan bahwa kemampuan berpikir kritis selama pemberian simulasi pada kedua kelas mengalami perbedaan yang cukup signifikan. Hal ini dapat diutarakan perbedaan hasil yang didapat keduannya yaitu hasil eksperimen saat sebelum (pretest) sebesar 11,19 yang mana untuk minimum diperoleh terkecil 5 dan untuk nilai maksimum diperoleh 25 serta standar deviasi 5,89. Hasil eksperimen saat sesudah (posttest) sebesar 88,09 yang mana untuk minimum diperoleh terkecil 75 dan untuk nilai maksimum diperoleh 100 serta standar deviasi 8,288. Sedangkan Hasil kontrol saat sebelum (pretest) sebesar sebesar 9,318 yang mana untuk nilai minimum peserta didik 5 dan untuk nilai maksimum 20 serta standar deviasi 4,16. Hasil kontrol saat sesudah (posttest) sebesar 80,00 yang mana untuk nilai minimum peserta didik 75 dan untuk nilai maksimum 95 serta standar deviasi 5,345.

Kemudian setelah memenuhi hasil uji normalitas, dan homogenitas. Pada kesempatan ini melakukan uji $t$-test didapat $t$ test $>t$ table $(3,82>1,99)$ maka Ho ditolak dan Ha diterima. Dengan demikian bahwa sungguh sangat diperlukan bagi pendidik terutama pembelajaran praktikum mengingat masih pandemi saat ini yang dibatasi kegiatan untuk bertatap muka terutama kegiatan belajar. Demi kelancaran, keaktifan, dan kekritisan mahasiswa dalam belajar tentukan penggunaan multisim dengan virtual lab dibutuhkan saat praktikum untuk dianalisis dan dikaji kebenaran.

\section{UCAPAN TERIMAKASIH}

Terima kasih saya ucapkan kepada pihak jurusan pendidikan teknik elektro yaitu Dra. Nontje Sangi, M. Pd yang telah berkesempatan kepada peneliti untuk melakukan penelitian selama 2 bulan.. Tidak lupa pula peneliti mengucapkan terima kasih kepada dosen pengampu mata kuliah praktek rangkaian listrik oleh Bapak Jane Devi Ticoh, M.T yang telah memberikan kesempatan untuk melakukan penelitian di kelas praktek rangkaian listrik serta beserdia memberikan saran, arahan dan bimbingan baik secara sistematika yang baik hingga bisa menyelsaikani jurnal.

\section{REFERENSI}

Argaheni, N. B. (2020). Sistematik Review: Dampak Perkuliahan Daring Saat Pandemi COVID-19 Terhadap Mahasiswa Indonesia. PLACENTUM: Jurnal Ilmiah Kesehatan Dan Aplikasinya, $\quad 8(2), \quad 99$. https://doi.org/10.20961/placentum.v8i2. 43008

Ayuningtyas, P., Soegimin, W. W., \& Supardi, Z. A. I. (2017). Pengembangan perangkat pembelajaran fisika dengan model inkuiri terbimbing untuk melatihkan keterampilan proses sains siswa sma pada 
materi fluida statis. JPPS (Jurnal Penelitian Pendidikan Sains), 4(2), 636647.

Báez-López, D., \& Guerrero-Castro, F. E. (2011). Circuit analysis with Multisim. Synthesis Lectures on Digital Circuits and Systems, 35, 1-198. https://doi.org/10.2200/S00386ED1V01 Y201109DCS035

Dalgarno, B., Bishop, A. G., Adlong, W., \& Bedgood Jr, D. R. (2009). Effectiveness of a virtual laboratory as a preparatory resource for distance education chemistry students. Computers \& Education, 53(3), 853-865.

https://doi.org/https://doi.org/10.1016/j.c ompedu.2009.05.005

Dewi, E. R. S., \& Prasetiyo, P. (2015). Virtual laboratorium dalam pembelajaran biologi materi Eubacteria berbasis karakter. Seminar Nasional Sains Dan Entrepreneurship II.

Herga, N. R., Čagran, B., \& Dinevski, D. (2016). Virtual laboratory in the role of dynamic visualisation for better understanding of chemistry in primary school. Eurasia Journal of Mathematics, Science and Technology Education, 12(3), 593-608.

Maksum, A. H., \& Saragih, Y. (2020). Analisis Penerapan Virtual Laboratorium Versus Reality Laboratorium. Jurnal TIARSIE, 17(2), 47. https://doi.org/10.32816/tiarsie.v17i2.72

Nurhayati, V. (2017). Penerapan Laboratorium Virtual Terhadap Kemampuan Berpikir Kritis Siswa Pada Konsep Sistem Eksresi. FKIP UNPAS.
Putra, I., \& Darma, K. G. (2009). Pendidikan berbasis teknologi informasi. Bali: Rakorda Disdikpora Bali.

Royani, I., Falahudin, I., \& Testiana, G. (2018). Pengaruh Media Edmodo Sebagai Basis E-Learning Terhadap Motivasi Belajar Siswa Pada Mata Pelajaran Ipa. Bioilmi: Jurnal Pendidikan, 4(1), 30-34. https://doi.org/10.19109/bioilmi.v4i1.173 4

Sastroprawiro, W. N. (2011). The Missing Abundance Mentality in Our Curriculum dalam Seri Pemikiran Mahasiswa: Ekonomi Indonesia di Mata Anak Muda UI. FEUI: Baduose Media.

Simbolon, D. H. (2015). Pengaruh model pembelajaran inkuiri terbimbing berbasis eksperimen riil dan laboratorium virtual terhadap hasil belajar fisika siswa. Jurnal Pendidikan Dan Kebudayaan, 21(3), 299-316.

Sutrisno, S. (2012). Kreatif Mengembangkan Aktivitas Pembelajaran Berbasis TIK. Referensi. https://repository.unja.ac.id/3540/

Tüysüz, C. (2010). The Effect of the Virtual Laboratory on Students' Achievement and Attitude in Chemistry. International Online Journal of Educational Sciences, 2(1).

Wijaya, M. S. (2017). Pengaruh Praktikum Virtual Terhadap Lampung 1438 H / 2017 M Pengaruh Praktikum Virtual Terhadap $\begin{array}{lllll}1438 & H & / & 2017 & \text { M. }\end{array}$ http://repository.radenintan.ac.id/285/

Williams, J. D., \& Williams, J. (2011). How Science Works Teaching and Learning in the Science Classroom. Continuum. 